\title{
LOS INTENTOS DE EXTERMINIO NAZI DE LOS HOMOSEXUALES EN LA LITERATURA \\ THE ATTEMPTS TO EXTERMINATE HOMOSEXUALS FROM LITERATURE BY NAZIS
}

\author{
CHRISTINA HOLGADO SÁEZ ${ }^{1}$
}

Universidad de Granada

Los judios, los homosexuales y los gitanos [...] eran los prisioneros que sufrían con mayor frecuencia y severidad las torturas y golpes de los SS y de los capos.

Se nos describía como la escoria de la humanidad, como gente sin derecho a vivir en suelo alemán que debía ser exterminada [...] Pero la última basura de esta escoria la constituíamos nosotros, los triángulos rosas.

Heger, 2002: 38 .

\section{Resumen}

El nacionalsocialismo constituye uno de los períodos más infames de la historia. Esta afirmación se confirma por una gran cantidad de literatura que retrata fielmente las atrocidades cometidas. Uno de los grupos más severamente perseguidos, torturados y abusados sexualmente fue la comunidad homosexual, conocida burlonamente en los círculos del Tercer Reich como "triángulos rosas." Este artículo analiza dos biografías publicadas entre los siglos XIX y XX.

Palabras clave: homosexuales, parágrafo 175, código penal, Tercer Reich, grupos torturados

\begin{abstract}
National Socialism constitutes one of the most infamous periods in history. This claim is solidly supported by a wealth of literature that faithfully portrays the committed atrocities. One of the most severely prosecuted, tortured and sexually abused groups was the homosexual community, derisively known in the Third Reich circles as 'pink triangles.' This paper analyzes two biographies of pink triangles that were published between the $19^{\text {th }}$ and $20^{\text {th }}$ centuries.
\end{abstract}

Key words: homosexual, paragraph 175, criminal law, Third Reich, abused groups

${ }^{1}$ Universidad de Granada. Correo-e: cholgadosaez@ugr.es. Recibido: 05-07-2017. Aceptado: 14-112017. 
El genocidio es el crimen por excelencia, el mayor crimen del que cabe hablar y el mayor atentado contra los derechos humanos. Un crimen que no ha perdido ni perderá su actualidad; ha marcado especialmente el siglo XX y continúa produciéndose en el siglo XXI (Camboya, ex Yugoslavia, Ruanda, Sudán, Burundi, Kosovo, Guatemala, Liberia, el caso kurdo, Darfur, etc.). Las formas de aparición del genocidio son tan variadas como sus motivos y hechos desencadenantes. Por ello, la Comunidad Internacional ha intentado repetidamente configurar este tipo de conductas y asignarles una estructura jurídica que favoreciera su persecución (Gómez, 2010: 973), amparándose en la protección de los principios y derechos que la humanidad reconoce a todos los seres humanos por el mero hecho de serlo (González, 2016: 432). La Convención para la prevención y sanción del delito de genocidio de 1948 proporciona por primera vez una definición jurídica del mismo. Posteriormente, el Estatuto de Roma de la Corte Penal Internacional tipificó este tipo de comportamientos en su artículo 6 (homicidio, agresiones sexuales y lesiones graves, y sometimiento a condiciones de vida destructiva).

Pero el que se tiene por "el prototipo canónico del fenómeno genocida" es el que los nazis perpetraron contra los judíos, entres otras minorías sociales, hasta el punto de que se trata de "la tragedia humana más espantosa y atroz registrada en la historia hasta el presente" [sic.] (Moradiellos, 2009: 17-21). La tipificación primigenia del crimen de genocidio aparece en la resolución 96-I (11 de diciembre de 1946) de la Asamblea General de Naciones Unidas. A pesar de su antigua existencia, la evolución del propio crimen se distribuye en cuatro períodos: primero, recuperación del montaje antijudío de los siglos XVIII y XIX, acusándolos de capitalistas, avaros, explotadores laborales, agitadores, violentos y comunistas; segundo, se produce un salto cualitativo con dos acciones distintas, por un lado, la puesta en marcha gradual de acciones eventuales contra el sujeto social, del otro, la vinculación con las penas de cuerpos jurídicos, refrendando las prácticas discriminatorias, e.g. ejercer determinadas profesiones, limitación de la propiedad, en el ejercicio de la ciudadanía, y en la posesión (Sánchez, 2016: 3); tercero, la incomunicación espacial delimitando territorios prohibidos y permitidos, e.g. los guetos y los campos de concentración y de exterminio; y cuarto, la intensificación de la debilidad física y psíquica, restando fuerzas a las víctimas y originando las condiciones oportunas para la industrialización de los procesos de exterminio.

La excepcionalidad del genocidio nazi reside en la racionalidad técnica con que se llevó a cabo, convirtiéndose en un moderno matadero industrial con un claro propósito exterminador. A diferencia del pueblo judío que observó el fin de su sufrimiento con la caída del nazismo, el colectivo homosexual, minoritario en números, siguió padeciendo su persecución y el castigo debido a la vigencia del parágrafo 175 del Código Penal Alemán. Ningún gobierno los reconoció como víctimas del nazismo hasta el siglo XXI, debido a que sus condenas se basaban en un delito tipificado penalmente, ergo, eran considerados criminales. Austria despenalizó la homosexualidad en 1971 y Alemania en 1994. 
Los intentos de exterminio nazi de los homosexuales reflejan las conductas típicas del genocidio (Rivaya, 2010), en general, y del físico, en particular. En el genocidio físico se incluyen los supuestos en que se produce la aniquilación o destrucción del grupo, causando la muerte o lesiones graves a alguno de sus miembros (artículo 607,1, $1^{\circ}, 2^{\circ}, 3^{\circ}$ y $5^{\circ}$ ) (Muñoz, 2015: 661). Muy poco se ha escrito sobre el hecho de que cientos de miles de personas fueron torturadas con sadismo hasta la muerte por el mero hecho de tener sentimientos homosexuales. La locura de Hitler y sus acólitos iba dirigida también contra ellos, considerados "epidemia nacional" en tanto en cuanto eludían el deber nacional de formar familias y provocando la pérdida de descendencia que se necesitaba urgentemente.

\section{EL PARÁGRAFO 175 DEL CÓDIGO PENAL ALEMÁN}

El nacionalsocialismo (1933-1945) constituye uno de los períodos más infames de la historia. Esta afirmación está sólidamente apoyada por una gran cantidad de evidencias, incluyendo una extensa variedad de películas y literatura que retratan fielmente las atrocidades cometidas contra ciertos grupos sociales durante este período. Uno de los grupos más severamente procesados, torturados y abusados sexualmente fue la comunidad homosexual, conocida burlonamente como "triángulos rosas". El código penal alemán de 1794, en su artículo 143, explicaba: “La fornicación contra natura, realizada entre personas del sexo masculino o de personas con animales, está castigada con una pena de cárcel de seis meses a cuatro años, además de la suspensión temporal de los derechos civiles". A raíz de la unificación alemana en el año 1871, el nuevo código penal introdujo el artículo 175, castigando con prisión las relaciones sexuales entre hombres. Así, se imponía el punto conservador del código de Prusia sobre el de las legislaciones de Baviera y Hannover que, en 1813 y 1840 respectivamente, habían despenalizado la homosexualidad imitando la influencia de la Ilustración Francesa (Heger, 2002: 9). Avanzando en el tiempo, la República de Weimar refleja la persecución criminal de homosexuales de forma esporádica e irregular; tanto es así que, el 16 de octubre de 1929, el Comité Científico-Humanitario dirigido por el famoso psiquiatra Magnus Hirschfeld logró, con el apoyo de los comunistas, que un comité especial del Reichstag aconsejara abrogar el artículo (Grau, 1995: 2). A pesar del apoyo adicional de numerosos intelectuales como Albert Einstein, Hermann Hesse, Thomas Mann, Rainer Maria Rilke, August Bebel, entre otros, a finales de 1929 el partido nazi obtuvo la suficiente mayoría en el Parlamento alemán (103 escaños) y la esperada reforma fue impensable. La criminalización de la homosexualidad se convirtió en un imperativo ideológico bajo el Nacional Socialismo, que la consideraba "antinatural" y cuyos protagonistas, los homosexuales, estaban eludiendo su deber nacional al objeto de formar familias. El régimen sostenía que estas prácticas se estaban convirtiendo rápidamente en una "epidemia nacional" y, por ende, dirigiéndose hacia la pérdida de descendencia que se necesitaba urgentemente (Zinn, 2016: 81):

Si admito que hay de uno a dos millones de homosexuales, esto significa que un $7 \mathrm{u} 8 \%$ de los hombres son homosexuales. Y si la situación no cambia, significa que nuestro pueblo estará infectado por esta enfermedad contagiosa [...] A largo plazo, ningún pueblo podría resistir 
semejante perturbación de su vida y de su equilibrio sexual [...] La homosexualidad impide todo rendimiento, destruye todo sistema basado en el rendimiento. $Y$ a eso se une el hecho de que un homosexual es un hombre radicalmente enfermo en el plano psíquico. [...] Nosotros hemos de comprender que si este vicio continúa extendiéndose en Alemania sin que lo combatamos, será el final de Alemania, el fin del mundo germánico.

“Discurso de Heinrich Himmler sobre la homosexualidad", 18/02/1937. (Toran 2005: 41).

Con todo, el sexo entre hombres abandonó la esfera privada para convertirse más bien en un acto de traición nacional.

Las persecuciones de estos hombres se vieron refrendadas por el parágrafo 175 del Código Penal Alemán, que en su versión del 28 de julio de 1935 introdujo su agravamiento y ampliación en el contenido. La versión modificada de esta ley amplió el hostigamiento de los homosexuales atendiendo a la extensión de la definición de "actividades indecentes criminales entre hombres", y estipulando severas condenas para los denominados "delincuentes". El apartado 175a estipulaba el internamiento en un centro penitenciario entre 1 y 10 años para casos extremos. Los apartados 174 y 176 recogían la "seducción", también considerada un acto homosexual, con menores de 14 hasta 20 años, así como con deficientes. No obstante, para un civil, el mero hecho de una prueba o convicción de su homosexualidad conducía a su juicio y posterior internamiento en un campo de concentración, i.e. un beso, una mirada, una carta, un gesto, un abrazo e incluso material de contenido homo-erótico.

En 1928 se estimaba en 1.5 millón el número de homosexuales; entre 1933 y 1945 la policía arrestó a unos 140.000 hombres por violar el parágrafo 175; 50.000 fueron sentenciados y la mayoría de estos hombres cumplió la sentencia en prisiones, aunque tampoco se incluyen aquellos hombres que fueron arrestados y enviados a los campos sin la celebración de un juicio. Sin embargo y siguiendo una directiva de la Gestapo del 4 de abril de 1938, entre 5.000 y 15.000 del total de las sentencias se cumplieron en los campos de concentración sufriendo crímenes contra la humanidad; 5.000 hombres perecieron en los campos de concentración (Plant, 1986: 154). Heinrich Himmler consideró tan crucial la persecución de los homosexuales que estableció en 1936 la "Oficina Central del Reich para la Lucha contra la Homosexualidad y el Aborto" (Reichszentrale zur Bekämpfung der Homosexualität und Abtreibung). Dicha oficina se encargaba de reunir información sobre hombres condenados -o sospechosos- de ser homosexuales y, seguidamente, lo habitual consistía en perseguirlos. El descenso en condenas después de 1938 se explica por el hecho de que los nazis enviaron a los homosexuales inmediatamente a prisión o a un campo de concentración. Sin embargo, los procedimientos judiciales tras 1938 llegaron a ser una gran pérdida de tiempo y de personal (Rector, 1981: 120).

El propósito de este trabajo persigue mostrar cómo los triángulos rosas fueron perseguidos bajo los auspicios del código penal alemán. Para tal fin, han sido seleccionadas las siguientes fuentes: (i) 2001 (Pierre Seel: Deportado Homosexual) y (ii) 2002 (Heinz Heger: Los hombres del triángulo rosa: Memorias de un homosexual en los campos de concentración nazi). 


\section{PERSEGUIDOS, TORTURADOS Y ABUSADOS SEXUALMENTE: SUS BIOGRAFÍAS}

\subsection{Detención, proceso judicial y confinamiento}

Joseph K. creció, junto a sus tres hermanas menores, en el seno de una familia pequeño burguesa de estricta moral católica. Su padre era un alto funcionario del estado alemán. Contaba con 24 años cuando fue detenido en 1942 y su condena se estableció en seis meses de cárcel. Por aquel entonces trabajaba en la oficina de Correos. Fue requerido para que se personase en el cuartel general de la Gestapo. Un oficial del alto rango se encargó del interrogatorio:

Eres un marica, un homosexual, ¿lo admites? No, no, no es cierto (balbuceé, del todo sorprendido por su acusación, que era lo último que esperaba) ¡No me mientas, maricón de mierda! (gritó con enfado). Tengo pruebas fehacientes, ¡mira esto! Sacó del cajón del escritorio una fotografía de tamaño postal y me la mostró. ¿Lo conoces? [...] Era una instantánea que alguien nos había hecho a Fred y a mí. Estábamos abrazados de los hombros como dos amigos. "Sí, es mi amigo y compañero de clase Fred." - Con que sí [...] Habéis estado haciendo cochinadas juntos, ¿lo confiesas? Su voz, fría y cortante, estaba llena de desprecio. Negué con la cabeza [...] El doctor tomó la foto y le dio la vuelta. En la parte posterior estaba escrito: “A mi amigo con cariño eterno e ínfimo afecto." [...] Debe de haber caído en manos extrañas, pensé fugazmente [...] ¿Es tu letra y tu firma? Asentí [...] ¿Lo ves? - Dijo con satisfacción y jovialidad, venga, firma aquí. Me pasó una hoja escrita hasta la mitad que firmé con mano temblorosa. Ese mismo día me condujeron a los calabozos. (Heger, 2002: 23)

A Joseph K. le fueron rechazadas sus peticiones para informar a su madre de dónde se encontraba. Posteriormente fue sometido a una meticulosa inspección física: obligado a desnudarse por completo para comprobar que no llevaba oculto ningún objeto prohibido, e incluso hubo de doblar la cintura y abrir las piernas (Heger, 2002: 25), incluyendo el momento del rapado del vello púbico. Fue condenado por un tribunal austríaco según el artículo 175 del código penal, y acusado de comportamiento sexual reiterado. Su pena de trabajo se tradujo en seis meses de cárcel, endurecida con un día de ayuno al mes. El procedimiento contra Fred -su amante-, que figuraba en una foto sustraída (Joseph K. se la había regalado a Fred en la Navidad de 1938 y en ella aparecía "A mi amigo con cariño eterno e íntimo afecto"), fue sobreseído por enajenación mental:

Algún poder superior debió meter baza e influir en el proceso judicial. Me imagino que el padre de Fred, un importante personaje del Tercer Reich, hizo uso de sus influencias y consiguió mantener a su hijo fuera del proceso. (Heger, 2002: 27).

Fue trasladado a la prisión del distrito I de Viena y ubicado en una celda individual. Se encargaba de servir la comida tres veces al día, de celda en celda; y una vez por semana de recoger las camisas de los prisioneros y devolverlas limpias. Una vez hubo cumplido su condena, tuvo que permanecer bajo custodia mediante la solicitud tramitada por la Central de Seguridad del Reich. Posteriormente sería deportado a un campo de concentración en un "transporte colectivo":

La noticia me cayó como una bomba, pues por otros prisioneros que habían vuelto de campos de concentración para asistir a juicios sabía que a nosotros, los "maricones", y a los judíos, se 
nos torturaba hasta la muerte en los campos, y que pocas veces salíamos vivos de ellos. Pensaba que exageraban y lo pintaban todo negro para fastidiarme. Desafortunadamente descubrí que era completamente cierto. (Heger, 2002: 29)

La pesadilla para Pierre Seel comenzaría con la denuncia por el robo de un reloj con significativo valor sentimental, hecho que supondría un antes y un después: de un ciudadano robado acabaría abandonando la comisaría como un "homosexual vergonzante" (Seel y Le Bitoux, 2001: 21). Ignoraba que su nombre había sido incorporado al fichero policial de los homosexuales de Mulhouse (Alsacia). La invasión alemana, tres años después, descubrirá el secreto a sus padres. La ocupación alemana y el traspaso de poderes obligaba a los vencidos a poner a disposición de los vencedores sus documentos. Realmente llamativo suponía la existencia de un fichero homosexual que según el código de Napoleón de 1804 no sancionaba la homosexualidad. Sin embargo, nuestro protagonista desconocía el macabro destino que los homosexuales alemanes habían sufrido desde 1933. El 3 de mayo de 1941 Pierre Seel se personó en las oficinas de la Gestapo tras ser convocado el día 2 del mismo mes. Tras reconocer a algunos jóvenes en la habitación a la que fue conducido bruscamente, se procedió a su interrogatorio en una habitación separada:

Pronto, el SS estaba enfrente de mí, tras haber cerrado violentamente mi expediente, me trató de "Schweinehund", de "perro asqueroso", es decir, de maricón de mierda. El interrogatorio no había hecho más que comenzar. ¿Conocía a otros homosexuales? ¿Cuáles eran sus nombres y direcciones? ¿Había oído hablar de tal o cual? ¿No era verdad que a tal eclesiástico le gustaban mucho los jóvenes? ¿Cuáles eran nuestros lugares de encuentro? De hecho, sabía mucho más que yo. Permanecí callado. (Seel y Le Bitoux, 2001: 30)

A Seel le extrañaba que la Gestapo tuviera conocimiento de su homosexualidad, ya que hasta ese momento nadie había mostrado pruebas de ello. No obstante, un SS le mostró el atestado firmado a los diecisiete años de edad, cuando denunció a un oficial de policía francés el robo de su reloj. Pierre Seel se mantuvo sin declarar para evitar delatar a otros homosexuales de Mulhouse. Como consecuencia los SS empezaron a golpearlos de forma intermitente, gritando, amenazando y agrediendo. Este comportamiento agresivo de los SS, cuyas prácticas no solo se circunscribían a los campos de concentración, comenzaba en algunos casos en los interrogatorios antes de iniciarse el procedimiento judicial. Pierre Seel relata:

Después de haber debido repetir veinte veces, durante 10 horas seguidas, las mismas palabras, vimos que sacaban las listas de las carpetas. Teníamos que firmarlas. Confirmar de rodillas sobre una regla de madera que todos aquellos hombres constituían la lista de homosexuales de Mulhouse. Las paredes hacían resonar nuestros gritos. A veces nos cambiaban de despacho. También nos pedían que identificáramos a los otros torturados, los capturados aquel día. Entonces nuestras miradas aterrorizadas se cruzaban [...] El engranaje de violencia se aceleró. Crispados por nuestra resistencia, las SS empezaron a arrancar las uñas de algunos de nosotros. Rabiosos, rompieron las reglas sobre las que estábamos arrodillados y se sirvieron de ellas para violarnos. Nuestros intestinos fueron perforados. La sangre salpicaba por todos los lados. Oigo todavía nuestros atroces gritos de dolor. Cuando volví a abrir los ojos, tuve la impresión de estar en la trastienda de una carnicería [...] La tortura había sepultado cualquier veleidad de reflexión. Una violencia pura, de las que destruyen siempre. Pero para nuestros torturadores fue una pobre victoria, ya que sí firmé el documento, como los demás, para cesar de sufrir, las manchas de sangre lo hacían ilegible. [...] Se nos envió a la cárcel de Mulhouse [...] Tuve tiempo 
de observar que muchos de ellos [...] habían sufrido también graves torturas. (Seel y Le Bitoux, 2001: 31)

Nuestro protagonista estuvo encarcelado 18 días y, posteriormente, fue trasladado al campo de Schirmeck el 13 de mayo de 1941. Carecía de defensa jurídica dado que la Gestapo tenía su propia ley. Una vez alcanzaron el campo les esperaban una lluvia de golpes:

Tuvimos que correr, arrastrarnos, correr y arrastrarnos de nuevo. Pronto, lo que quedaba de nuestra vestimenta civil no era más que jirones. Las órdenes gritadas eran invariablemente seguidas de golpes en cuanto los SS se nos acercaban. (Seel y Le Bitoux, 2001: 34)

Tras una ducha helada se procedía al rapado que, en el caso de Seel y debido a su estilo "zazou", se benefició irónicamente de un trato de favor. El detenido, encargado del rapado, le desolló el cráneo, dibujándole una cruz gamada. Su uniforme se distinguía por una cinta azul en el chaquetón y en el gorro, ubicándolo en el grupo de los católicos o asociales, además de los homosexuales: "El delito sexual era una carga adicional en la identidad carcelaria" (Seel y Le Bitoux, 2001: 40).

\subsection{Los campos de concentración: experimentación médica, torturas, trabajos forzados y} hambre

Entre 1933 y 1945 aproximadamente 10000 hombres fueron confinados en campos de concentración por sus tendencias homosexuales. A partir de 1937 y 1938 se les identificó como grupo de detenidos con un triángulo rosa cosido en el pijama de rayas; con anterioridad a esa fecha este colectivo debía mostrar en su ropa una gran "A" (Arschficker -maricón-) (Zinn, 2016: 79). Los homosexuales deportados carecían de la más nimia posibilidad de ser liberados. Otros métodos de aniquilación consistían en la experimentación médica con inyecciones (Rector, 1981: 130-131) en manos de científicos y doctores del régimen, que en absoluto consideraban sus acciones como un sadismo deliberado. Los homosexuales, en su mayoría, coincidían con el perfil físico y la edad del soldado medio alemán. La biografía de Pierre Seel relata el siguiente hecho sobre la experimentación médica:

Me aterrorizaba cada vez que los altavoces citaban mi nombre, porque a veces era para practicar sobre mí monstruosidades experimentales. La mayor parte del tiempo consistían en inyecciones muy dolorosas en las tetillas [...] Para realizar sus inyecciones les gustaba lanzar sus jeringas en nuestra dirección como se lanzan dardos en la feria. Un día de sesión de inyecciones, mi afortunado vecino se derrumbó, perdiendo el conocimiento. La jeringa le había alcanzado el corazón. No le volvimos a ver nunca. (Seel y Le Bitoux, 2001: 43)

Joseph K. describe la tortura de los baños de agua a temperaturas bajo cero como parte de las prácticas médicas:

A quien fuera sorprendido en la cama con el calzoncillo puesto, o con las manos debajo de las mantas -casi todas las noches se efectuaban controles-, se le conducía al exterior y se le echaban varios baldes de agua encima, luego debía permanecer de pie a la intemperie durante más de una hora. Muy pocos superaron este procedimiento. Lo menos que te podía pasar era que cogieras una pulmonía, y era raro el homosexual que salió vivo de la enfermería: los que llevábamos el triángulo rosa éramos muy codiciados para servir como conejillos en experimentación médica que generalmente terminaban en la muerte. (Heger, 2002: 41) 
Otras conductas deleznables ejecutadas en los homosexuales incluían la tortura y desmembración corporal por parte de los perros guardianes del campo de concentración. Seel detalla con minuciosidad un episodio desgarrador:

Un día los altavoces nos convocaron a una sesión a celebrar en la plaza de recuentos. Gritos y ladridos hicieron que fuéramos todos rápidamente [...] Yo imaginaba que nos iba (el comandante del campo) a reiterar su fe ciega en el Reich [...] Horrorizado, reconocí a Jo, un tierno amigo de 18 años. No lo había visto antes en el campo [...] en mi dolor, no me enteré en absoluto del contenido de la sentencia de muerte [...] Después los altavoces difundieron una vibrante música clásica mientras los SS le desnudaban. Luego lo colocaron violentamente en la cabeza un cubo de hojalata. Azuzaron hacia él a los feroces perros guardianes del campo, los pastores alemanes, que lo mordieron primero en el bajo vientre y en los muslos antes de devorarle ante nuestros ojos. Sus gritos de dolor eran amplificados y distorsionados por el cubo dentro del que seguía su cabeza. Rígido pero vacilante, con los ojos desorbitados por tanto horror y las lágrimas corriendo por mis mejillas, rogué fervientemente que perdiese el conocimiento con rapidez. (Seel y Le Bitoux, 2001: 45 y 46)

Joseph K. expone con gran minuciosidad la desproporcionada tortura denominada "baño genital" por parte de unos guardias ebrios a un prisionero homosexual:

Un triángulo rosa fue torturado hasta la muerte en el búnker. Completamente desnudo, le encadenaron las manos a un garfio de la pared, de modo que el cuerpo colgara completamente estirado y los pies no tocaran el suelo. Le mantenían las piernas abiertas de par en par, e igualmente atadas [...] El primer jueguecito [...] consistió en hacerle cosquillas con unas plumas de ganso en la planta de los pies, en las ingles, en las axilas y en otras partes del cuerpo [...] Los guardias, borrachos como cubas [...] querían divertirse más. Hicieron que el capo del búnker trajera dos tazones de hojalata, uno con agua fría y otro con agua caliente [...] Te vamos a escaldar un poquito los huevos y después te los refrescaremos [...] El procedimiento se repitió varias veces hasta que la atormentada víctima perdió el conocimiento [...] Entonces le echaron encima un balde de agua fría para que se reanimara, y las sádicas bestias uniformadas reanudaron la tortura [...] del escaldado escroto de la víctima colgaban jirones de piel [...] Se les ocurrió un nuevo tormento [...] Tomó una escoba e introdujo buena parte del mango en el ano del infeliz. (Heger, 2002: 109-110)

Este mismo superviviente detalla la tortura del árbol (Baumhängen), una práctica común en la mayoría de campos de concentración:

Ser colgado en el árbol era uno de los castigos más crueles que te podían imponer. Se trataba de un grueso poste de madera muy largo con un gancho de hierro a unos 2 metros de altura [...] $\mathrm{Al}$ transgresor se le ataban las manos a la espalda y luego se le colgaba del gancho. El peso del cuerpo caía en los hombros de tal manera que el condenado solo lograba resistir su propio peso durante poco tiempo. En cuanto le flaqueaban, los hombros se le descoyuntaban, ocasionándole horrendos dolores [...] Era uno de los castigos más temidos: cuando un preso colgaba del árbol, sus alaridos de dolor y sus gritos de auxilio se podían oír en el extremo remoto del campo. (Heger, 2002: 91)

El objetivo principal de las SS consistía en la destrucción de este colectivo mediante los trabajos forzados, principalmente en las minas de arcilla. El trabajo en el yacimiento era lo más duro que uno se pudiera imaginar. Tanto en verano como en invierno y diariamente, con los hombros debían empujar un número establecido de carros llenos de arcilla hasta las máquinas de modelado y los hornos de cocción. La producción no podía interrumpirse. Los capos que supervisaban el trabajo, no escatimaban en penalidades, hasta tal punto que algunos prisioneros dejaban 
deliberadamente que los carros les aplastaran los dedos, las manos enteras o los pies para ser enviados a la enfermería, de la que nunca salían vivos. Estos homosexuales engrosaban la interminable marea de conejillos de indias para experimentación médica. Joseph K. sobre los trabajos forzosos en la cantera:

Las órdenes del régimen nazi de llevar a cabo en los territorios del Tercer Reich una drástica purga de homosexuales, eran "elementos degenerados" del pueblo alemán que debían ser exterminados, las cumplían los esbirros de las SS con sádica eficiencia y celo. Pero no se trataba de exterminarnos de forma inmediata, sino de torturarnos hasta la muerte con crueldad y brutalidad, con raciones de hambre y extremos trabajos forzados. (Heger, 2002: 55)

La cantera se cobró muchas vidas como resultado del gran número de accidentes, la mayoría de los cuales eran provocados por las SS y los capos. (Heger, 2002: 61)

Finalizado el recuento de cada prisionero, Pierre Seel regresaba a los trabajos forzados en la cantera, y expresa el recibimiento por parte de los SS:

Teníamos que nivelar los caminos entre barracones arrastrando, a latigazos, un rodillo compresor cuyas correas nos cortaban el vientre, provocándonos violentos dolores de vientre. (See y Le Bitoux, 2001: 39)

La falta de alimentos en los campos de concentración era un hecho habitual, las tres comidas diarias se componían en alimentos ricos en agua, esto es, agua y verdura, y en algunos casos un trozo de pan duro o mohoso. Como consecuencia, los prisioneros que estaban sometidos a trabajos forzosos en las canteras de los diferentes campos, sufrían el deterioro físico y una sensación de hambre poco más que inhumana, que los arrojaba a situaciones degradantes, como manifiesta Pierre Seel:

Una de las peores cosas cotidianas de las que guardo recuerdo es el hambre. Era cuidadosamente mantenida por nuestros guardianes y fue fuente de numerosas peleas. El hambre merodeaba y nos animalizaba, haciéndonos asumir considerables riesgos. A veces, cuando estaba encargado de la limpieza de las jaulas de los conejos, devoraba subrepticiamente algunas zanahorias [...] El hambre volvió loco a algunos de nosotros. Me acuerdo de un detenido que estaba a menudo cerca de las letrinas, consistentes en algunas planchas encima de una agujero maloliente al que los más débiles se escurrían a veces. Él merodeaba siempre por allí ya que era donde más moscas había. Cada vez que conseguía atrapar una sofocaba grititos de contento. (Seel y Le Bitoux, 2001: 43-44)

Arrancados del sueño a las 6 de la mañana, ingeríamos una tisana desleída y un cuarto de hogaza de "Kommisbrot", una especie de pan negro generalmente duro o mohoso [...] Hacia el mediodía nos servían una sopa clara con una rodaja de salchichón [...] Dos cacillos de sopa de nabos terminaban nuestra jornada. (Seel y Le Bitoux, 2001: 36).

El 6 de noviembre de 1941, cuando Seel contaba con 18 años, fue liberado del campo de concentración. El comandante del campo, Karl Buck, le expresaba:

... si tiene la tentación de decir cualquier cosa sobre lo que ha visto o ha vivido en este campo, si decepciona a las autoridades del Reich, evidentemente no tardará en volver a estar entre alambradas. (Seel y Le Bitoux, 2001: 48).

Pierre Seel tenía que fichar en la Gestapo durante cuatro meses. El 21 de marzo de 1942 sería reclutado para el RAD (el Reich Arbeitsdienst). Con la finalidad de incrementar su humillación tuvo que llevar el brazalete con la cruz gamada. Fue destinado al taller del aeropuerto militar de Güterlosh, cerca de la frontera holandesa. Regresó el 26 de septiembre de 1942, al mes siguiente tuvo que enrolarse 
obligatoriamente en la Wehrmacht. Un decreto establecía el enrolamiento sistemático de los alsacianos lorenenses. El destino final era Yugoslavia a través de Austria. Tras ser herido y hospitalizado en la Cruz Roja, Pierre Seel es convertido en soldado auxiliar y trasladado a Berlín como chupatintas en un cuartel. Su exilio duró 4 años hasta que el 7 de agosto de 1945 regresa a París. Contaba con 22 años. Había regresado con el cuerpo destrozado por tantas penurias y la cabeza devastada por demasiados horrores.

En cuanto a Joseph K., la pena de siete meses se transformó en seis años de penalidades, torturas y sometimientos. En la noche del 22 de abril de 1945 unos guardias de las SS lo abandonan en un campo junto a un grupo de homosexuales austriacos por temor a la llegada cercana de las fuerzas aliadas. Tras regresar del campo de concentración no fue readmitido en su antiguo puesto como empleado de la oficina de Correos, por tanto decidió trabajar como vendedor de artículos para el cuidado del cuero y el calzado; a la edad de 52 años se cambiaría al ramo textil. En sus reflexiones sobre la nueva estampa de Alemania le resultaba arrogante considerar que el destino había escogido a este país para dirigir y gobernar Europa, motivo suficiente como para no comulgar ni con los nuevos amos nazis de Austria ni con su ideología, que no llegaba a comprender:

¿Qué había hecho yo para tener que pagar de esa manera? ¿Qué crimen infame había cometido o qué daño había causado a la sociedad? Había amado a un amigo mío, no a un menor, sino a un hombre adulto de 24 años. No encontraba nada malo ni de inmoral en ello.

¿Qué clase de mundo es este y qué personas viven en él para decirle a un hombre adulto cómo y a quién debe amar? ¿No es cierto que cuantas más inhibiciones sexuales y complejos de inferioridad tiene un legislador, más se le llena la boca al hablar de los sentimientos supuestamente sanos de la sociedad? (Heger, 2002: 29).

Finalizada la guerra, el Ayuntamiento de Viena constituye una oficina provisional para los repatriados de los campos de concentración, lo que suponía la respuesta a una indemnización que reconociera sus derechos como perseguido durante la ocupación nazi y condenado por un delito tipificado penalmente; no obstante las autoridades rechazaron todas sus propuestas animándole a que cambiara su triángulo rosa por el rojo, icono de los presos políticos; en calidad de "sarasa" no obtendría ninguna ayuda. Desde 1971, año en que se despenaliza la homosexualidad en Austria, y hasta 1992 Joseph K. consigue que el estado austriaco le computara el pago de la pensión tras numerosas solicitudes y trámites de documentación. Nuestro protagonista fallecería con 80 años en 1994 sin recibir la indemnización por la persecución que sufrió.

\section{BIBLIOGRAFÍA}

Eschebach, I. (2016): Homophobie und Devianz. Weibliche und männliche Homosexualität im Nationalsozialismus, Berlin, Metropol Verlag.

Gomez Rivero, Ma .C. (2010): Nociones fundamentales de derecho penal. Vol. I: Parte Especial, Madrid, Editorial Tecnos. 
González Agudelo, G. (2016): “Lección 33. Delitos contra la comunidad internacional”, en J.M. Terradillos Basoco (coord.) (2016): Lecciones materiales para el estudio del Derecho Penal. Tomo III. Derecho Penal. Parte Especial (vol. II), Madrid, Iustel: 431453.

Grau, G. (2004): Homosexualität in der NS-Zeit. Dokumente einer Diskriminierung und Verfolgung, Frankfurt a.M., Fischer Taschenbuch Verlag.

Grau, G. (1995): Hidden Holocaust? Gay and Lesbian Persecution in Germany 1933-45, New York, Cassell Publisher.

Heger, H. (2002): Los hombres del triángulo rosa: Memorias de un homosexual en los campos de concentración nazi, Madrid, Amaranto.

Moradiellos, E. (2009): La semilla de la barbarie. Antisemitismo y holocausto, Barcelona, Ediciones Península.

Morsch, G., y Ley, A. (Eds.) (2007): El campo de concentración de Sachsenhausen 19361945. Acontecimientos y evolución, Großburgwedel, Metropol Verlag.

Muñoz Conde, F. (2015): Derecho Penal. Parte Especial, Valencia, Tirant lo Blanch.

Neumann, F. (2014): Behemoth. Pensamiento y acción en el nacional-socialismo, 1933-1944, Barcelona, Anthropos.

Plant, R. (1986): The Nazi War against Homosexuals. The Pink Triangle, New York, Owl Books.

Rector, F. (1981): The nazi extermination of homosexuals, New York, Stein and Day Publishers.

Rivaya García, B. (2010): “Genocidio y cine”, Revista InterseXiones, 1, 1-29.

Sánchez Reverte, R. (2016): "Referencia al crimen del genocidio", Revista de Estudios Jurídicos, 16, 1-19.

Seel, P. y Le Bitoux, J. (2001): Pierre Seel: Deportado Homosexual, Barcelona, Bellaterra.

Torán, R. (2005): Los campos de concentración nazis. Palabras contra el olvido, Barcelona, Editorial Península.

Zinn,A.(2016): “Homophobieund männlicherHomosexualitätinKonzentrationslagern. Zur Situation der Männer mit dem rosa Winkel", en I. Eschebach (2016): Homophobie und Devianz. Weibliche und männliche Homosexualität im Nationalsozialismus, Berlin, Metropol Verlag: 79-96.

Zur Nieden, S. (2016): “Der homosexuelle Staatsfeind. Zur Radikalisierung eines Feindbildes im NS", en I. Eschebach (2016): Homophobie und Devianz. Weibliche und männliche Homosexualität im Nationalsozialismus, Berlin, Metropol Verlag: 23-34. 